\title{
THE INFLUENCE OF PRINTING, LAMINATION AND HIGH PRESSURE PROCESSING ON SPOT COLOR CHARACTERISATION
}

\author{
Renata TOMERLIN, Mario TOMIŠA, Damir VUSIĆ
}

\begin{abstract}
The food industry has recognized the important role that multi-layered, flexible packaging materials play and it uses them extensively within the packaging processes. Trends within food processing and packaging continuously encourage manufacturers to develop new technologies which extend a product's shelf-life. The samples that were the subject of research described in this paper are retort stand-up pouches made of multi-layered flexible material, the layers of which have been bonded with a laminating process that aims to both extend a product's shelf-life and stability, permitting the final processing of the finished product under aggressive regimes. It is intended that packaging, when subjected to graphic reproduction and high pressure processing, shall remain unchanged in all aspects, in particular the visual aspect that is the subject of the research. The samples were printed on polyester film (PET) using a rotogravure printing technique and laminated on aluminum (Al), oriented polyamide (OPA) and finally on inner polypropylene (PP) layers. The sample was monitored for the Vegeta Blue spot colorimetric difference in the $\mathrm{CIE} \mathrm{L}^{*} \mathrm{a}^{*} \mathrm{~b}^{*}$ space throughout the individual graphic reproduction phases and the final high pressure processing (HPP) of the finished product. The goal is to determine the size of the spot color colorimetric difference $\left(\Delta E^{*}\right)$ in relation to the defined formula and the established standard. On the basis of measured results, guidelines and recommendations for the correction and quality assessment of spot color reproduction throughout the entire process were defined, with the goal to minimize any deviation to the lowest possible level.
\end{abstract}

Keywords: CIE L*a*b*; colorimetric difference; food packaging; high pressure processing; spot color

\section{INTRODUCTION}

The packaging of a product was originally considered as anything that held, protected and stored its contents. It has evolved throughout history from its initial role to that of a key element and driver of a marketing mix. Simplicity has led to complexity and, aside from retaining the basic functional features, packaging has now acquired a number of new attributes. It communicates and is unique in its shape, is easily recognizable, uses intelligent materials and colors, applies unique coding and is interactive, biodegradable and, in some instances, edible. All of this and much more make up today's food packaging. Its design and attractiveness draw consumer attention to a shelf and encourage the purchase and consumption of products $[1,2]$. As color and form are the most recognizable design elements, each retail chain brand strives to achieve the spot color standardization that forms the dominant element of its visual identity. Throughout the packaging process, from its initial inception, i.e. the designer's idea, through production and final placement on the shelf, special attention is paid to the colorimetry and reproduction quality of all elements defining the visual design, especially those involving the spot color reproduction defined and permitted within the CIE L ${ }^{*} a^{*} b^{*}$ color space.

The packaging industry is one of the global leaders in industrial production and food packaging is the main segment within the whole packaging industry.

Numerous new food packaging products appear on the market every year and face high levels of competition and increased consumer demands. Every food product includes a food packaging system, and this has become an increasingly influential factor when a consumer decides to purchase a particular product when there is a choice of various brands of the same type of the product. Just as with food, food packaging must meet high quality and safety standards and comply with all legal requirements and regulations to achieve success on the market [3].

The composite multi-layer flexible packaging material was used to manufacture the samples used in the research presented in this paper, which included not only the different types of polymeric materials but also a layer of aluminum that provides an adequate barrier and adds container strength for all of the production processes to which the packaging shall be subjected. The packaging material is composed as follows (Fig. 1):

- Polyester PET $12 \mu$

- Aluminum Al $9 \mu$

- Oriented polyamide OPA $15 \mu$

- Polypropylene PP $75 \mu$.

The composition of this packaging material is suitable for High Pressure Processing (HPP). High pressure processing (HPP) is an industrially tested technology that offers a more natural, environmentally friendly alternative for pasteurization or shelf life extension of a wide range of food products [4]. Commercial high pressure and low temperature methods achieve inactivation of vegetative microorganisms by subjecting vacuum-sealed food in flexible packaging to treatment at hydrostatic pressures of $600 \mathrm{MPa}$ (or less) and initial temperatures lower than $40{ }^{\circ} \mathrm{C}$ for one to fifteen min. depending upon product application. A food product with packaging is subjected to treatment at 300,400 and $500 \mathrm{MPa}$ pressures for a defined time period of 5 and 10 minutes. Pressures above $400 \mathrm{MPa}$ at ambient temperature inactivate the vegetative flora (bacteria, virus, yeasts, molds and parasites) present in food, extending the products shelf life importantly and guaranteeing food safety. High Pressure Processing respects the sensorial and nutritional properties of food, because of the absence of heat 
treatment, and maintains its original freshness throughout the shelf life [5].

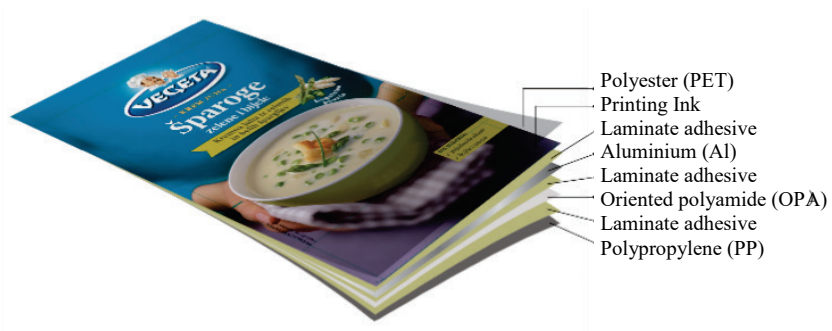

Figure 1 Multi-layered Stand-up Pouch Material

\section{FLEXIBLE MULTI-LAYERED FOOD PACKAGING}

Food packaging experienced its greatest expansion and flourishing in the second half of the $20^{\text {th }}$ century. This is partly due to the development and discovery of new polymer materials and partly due to increased food production as a result of population growth, urbanization, lifestyle changes, female employment and increasingly pronounced hygiene habits [6].

Packaging material is any material from which packaging is made, such as: glass, plastic, paper, cardboard, wood, metal multi-layered mixed materials and other materials [7].

Multi-layered mixed flexible material plays an important role within the packaging material segment. Multi-layered packaging is predicted to grow at an annual rate of $4.1 \%$, meaning an increase from 27.4 million metric tons in 2017 to 33.5 million metric tons in 2022 . The financial market share of flexible packaging material is growing annually by $4.3 \%$ and by 2022 this is expected to amount to 283 billion USD [8].

Historically, polymer materials have only been used as a packaging material for a short period of time and, from their initial mass use in the 1950s onto the present day, their properties have constantly improved, changed and been enhanced. Packaging materials are almost exclusively made from plastomers. A considerably smaller amount of duromers and elastomers are used as an auxiliary material for sealing lids and fasteners [9].

The polymers most commonly used in plastic packaging include:

- Polyethylene (PE),

- Polypropylene (PP),

- Styrene homo- and copolymers [polystyrene, (PS), styrene-acrylonitrile (SAN) and acrylonitrile butadiene styrene (ABS),

- Polyvinylchloride (PVC)

- Polyamide (PA)

- Polyethylene terephtalate (PET) and

- $\quad$ Polycarbonate (PC) [9].

Usually, these are divided into flexible and rigid packaging materials. Everything that has a thickness of up to $250 \mu(0.010 \mathrm{inch})$ is considered a flexible material or film, and everything thicker is considered a rigid polymer. However, in practice, this is not the most effective method of division as the stiffness of a material depends on the type of polymer. Therefore, for example, PVC (polyvinylchloride) or cellulose nitrate will already be rigid at $70-80 \mu$, whereas LD PE (low density polyethylene) will not be rigid even at $300 \mu[10]$.

Polymers are very rarely used in their original form, and in order to achieve good characteristics to be a packaging material, different additives are added during their production to improve their properties. In addition to the combination of different polymers, multi-layered flexible packaging is combined with other materials (e.g. paper and aluminum) that aim to increase endurance, packaging resistance and barrier properties.

Currently, a new EU Directive is being developed, and it is known as the SUP Directive (Single-Use Plastics). This Directive shall also partly cover the packaging materials primarily intended for snack products, beverage industry and in general all food intended for direct consumption without further processing [11]. A great deal of pressure has been applied to manufacturers of plastics and polymer materials relating to the adequate disposal and recycling of materials with a view to reducing marine pollution in seas, marinas and the environment in general. Regardless of its negative reputation and poor image, plastic has a number of benefits over other packaging materials and it is impossible to imagine life without it.

Only $1.5 \%$ of all oil and gas consumed in Europe is used as a raw material for the production of plastic packaging, while $90 \%$ is used for heating, transportation and energy production. If food is packaged with other packaging materials, the associated energy consumption would be doubled and greenhouse gas emissions would be almost tripled. This would also be accompanied by a $360 \%$ increase in packaging weight. It is the lightest packaging material. More than $50 \%$ of all European products are packed in plastic that only accounts for $17 \%$ of the total packaging weight of all products on the market. Furthermore, this weight has been reduced by $28 \%$ over the previous 10 years. Lightweight packaging means lighter loads and fewer trucks required to deliver the same amount of products, thus reducing energy consumption for transportation, $\mathrm{CO}_{2}$ emissions and transportation costs [12].

From the perspective of companies and consumers (users), packaging must achieve several goals:

- Identify a brand,

- Contain the product's description and valid information,

- Facilitate smooth transportation and product protection,

- Facilitate storage for the consumer and

- Enable easy consumption of the product [13].

All of this is possible with multi-layer flexible packaging as certain polymer materials provide an excellent printing substrate, look extremely attractive on the shelf and offer a range of options for additional effects, such as various lacquers, partial matte or glossy finishing, a metallic effect if a printed surface is laminated on an aluminum surface without white primer, etc. Additionally, handling, production and transportation of this type of packaging material is simple and allows for storage in ambient temperatures for an 
extended shelf life, provided of course that the packaging remains hermetically sealed and secured. A relatively new form of packaging on the Croatian market are stand-up pouches made of flexible multi-layered materials, suitable for sterilization and high pressure processing and practical for use and application. Stand-up pouches can take various forms, depending on the molding tool on the forming machine and the staples used, and they can include possible variants such as a sealing strip or laser perforations or indentations for easier opening. Depending on the combination of packaging materials, these may be transparent or contain an aluminum layer, but the latter are not suitable for heating in a microwave oven.

The retort stand-up pouches are the actual subject matter of this research. It defines the colorimetric difference of the Vegeta Blue spot color in the CIE L*a* ${ }^{*}{ }^{*}$ space applied to the packaging design to detect the phase of the process that causes the greatest colorimetric difference in relation to the defined standard and color formula. When shopping, customers are inclined to select certain products according to their individual habits and memorized characteristics. The main feature of Vegeta branded products is their recognizable blue color. Vegeta Blue is a color that should be kept within a strictly defined tolerance range $\left(\Delta E^{*} \leq 1\right)$, regardless of the type of packaging material, printing technique or finishing process). This is not a simple task at all, as it requires selecting an adequate supplier that understands the specifics of the printing technique, its alignment within the graphic preparation and design process and permanent quality control and measurement of colorimetric values within the CIE $L^{*} a^{*} b^{*}$ space throughout the entire graphic and technological process.

\section{RESEARCH METHODOLOGY}

This chapter describes the methodology used in this research and the impact of the individual phases of the graphic and technological process on the Vegeta Blue spot colorimetric difference. Standard values for the Vegeta Blue spot color were prescribed in Podravka Packaging Development Dpt., coordinated with the supplier. The results of the measurement of the CIE L* $a^{*} b^{*}$ color values and their colorimetric difference per processing stages were compared and colorimetric differences were observed compared to the defined standard and the set Vegeta Blue spot color formula. The measurement was taken after printing, lamination and high pressure processing. It indicated the stage at which the greatest colorimetric difference outside the tolerance area occurred and whether it could have an impact on consumer perception.

The graphical and technological process is divided into several stages. The first of these is the graphical design stage, which in some instances implies solely the application of visual elements to the already existing form and packaging material, and in certain situations this may mean designing a new form mainly in rigid plastic, glass, or metal packaging, which also requires the development of a new label, a shrink sleeve foil or another final package decoration. In such situations, this design process is more time-consuming and complex and requires the connectivity of designers, marketing experts, development engineers and specialist expertise from suppliers of certain packaging materials. Primary packaging is in most instances characterized by applied printing. In order to achieve excellent printing results, graphical preparation, customized to specific printing techniques and characteristics, is required. The printing phase is followed by lamination processes, die-cutting forming and sealing the retort stand-up pouch in this case. In addition to the processes listed above, the packaging that is the subject of this research is also exposed to the processing of a finished product, which in this instance means exposure to high pressure processing during which unwanted changes to the packaging material can occur, and that manifest in the form of de-lamination of the packaging material, separation of individual layers or changes in a polymer, which in turn can affect colorimetric difference and subsequently consumer perception.

\subsection{Design, Graphic Preparation and Printed Form Production}

For the purposes of the research presented in this paper, a design has been applied to the already existing technical drawing of the retort stand-up pouch produced by the Company Aluflexpack Novi from Umag. Packaging design usually begins with a good, clear and detailed brief for the agency and the designer. Since it was necessary to apply the Vegeta Blue spot color on as large area of the pouch that was the subject of this research as possible, the design was completed in the Podravka Design Studio and it included the tailoring of an already existing design to new dimensions. The Brief is usually drafted by the marketing team with expert support from development specialists, who mostly reduce the ideas of designers and marketing into a practicable and feasible framework.

The stand-up pouch constructed from a multi-layered packaging material onto which the design was applied has a total volume of $500 \mathrm{ml}$ and measures $140 \times 240 \mathrm{~mm}$. The format of the packaging that is the subject of research is part of the standard Aluflexpack Novi product range and formatted components of this shape are currently included in production. In addition to the design, a color measuring atlas has been applied on the back of the bag, which will be used in future studies relating to process of colorimetric difference.

The design and graphical preparations were completed in Adobe Illustrator CC. Color separation was completed in Esko ArtPro, Version 16.0.0 in Company Anilox. Separation for printing was performed by using seven colors (cyan, magenta, yellow, black, Vegeta Blue, reflex blue and white). A test print was performed on an Epson Stylus Pro WT7900 ink jet printer, which uses a Micro Piezo TFP head for printing. The printer color management software is GMG RIP and GMG FlexoProof, Ver.5.8.1.312. A test print using digital technology (GMG proof) was performed for quality control of all design elements. Podravka, which in this instance commissioned the design, received the final color separation and digital print, for quality control purposes. A 
signed digital print serves as a guarantee for the packaging supplier that all is in order and that the next stage of the process, namely the engraving of printed forms, can be embarked upon.

Separation was engraved from the application Collage, which was also used for installation and to define the following parameters:

- Lineature, $(70 \mathrm{~L} / \mathrm{cm}-101 \mathrm{~L} / \mathrm{cm}$, depends on color $)$,

- Individual separation angles, $\left(33^{\circ}-60^{\circ}\right.$, depends on the color),

- Tool angle, $\left(110^{\circ}-130^{\circ}\right.$, depends on the color $)$,

- Reproduction curve.

Preliminary prepared cylinders were then engraved on electronic engraving machines. The engraving was performed on an Ohio Gravure Tec. Inc. USA, Gravostar Spectrum Engraving Machine. The process was tailored to the parameters of the selected substrate and machine on which the printing was performed. In order for the print cylinders to be sufficiently durable to withstand printing on printing machines, they were finally processed with hard chrome plating, where a protective layer of chromium, several micro millimeters thick, was applied. Final quality control was performed by a visual inspection of the finished printed forms and the pattern was printed on a test print machine utilizing the original inks and consumer substrate (PET $12 \mu$ ) at the Aluflexpack Novi Print Shop by simulating the parameters of the printing machine. A test print was performed on a manually processed printing press. The test print, when obtained as described above, showed if there were any visible defects and if any corrections on print forms were necessary. The test print with engraved print forms was performed on Rotogravure Proofing Press, a test print machine produced by JM Heaford of the UK, on a HA $3500 \times 1800$ (Fixed Drum / Hydraulic Rotation) Model.

\subsection{Printing and Finishing}

The samples that are the subject of this paper have been printed by using the rotogravure printing technique. Rotogravure printing is a direct, intaglio printing technique. The print face is hollowed out in its printed form and the blank spaces are foremost [14]. The printing ink is applied on the entire print form during printing and later, a doctor blade removes the printing ink from the blank spaces (Fig. 2). By pressing the printing form onto the substrate, the printing ink is transferred to the substrate. The printing surface of the PET foil should be treated to be suitable for printing, which has a significant influence on surface tension and enables the ink to connect with the printing substrate [15].

This printing technique allows the reproduction of very small details, small font-sized text, excellent photographs and product views. The usual perception of rotogravure printing within the printing industry is that it is used in the printing of top class brand packaging which must be highquality. Quality remains the main feature of the printing technology, but in recent years, the producers of printing forms, i.e. engraving companies, have sought to reduce costs and automate the process. New, fast engraving heads use robotic arms and are fully automated, replacing human labor and they have led to significantly shorter delivery times, often no longer than a few days [16].

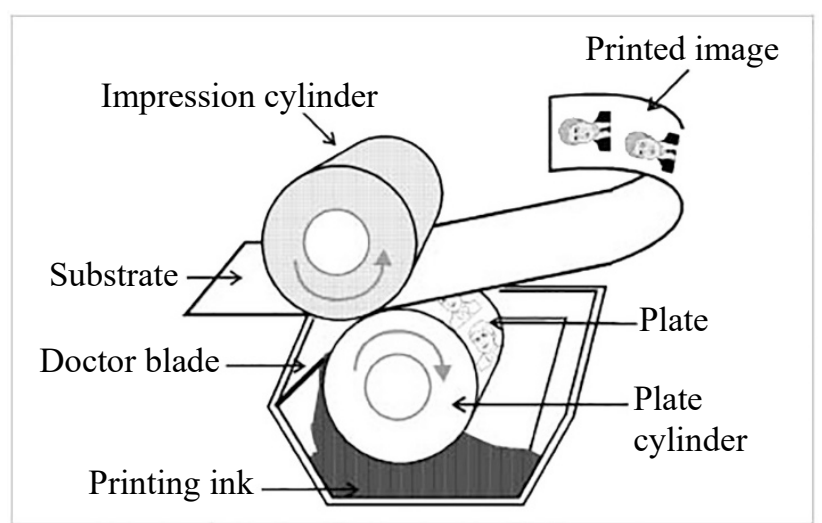

Figure 2 Rotogravure Printing Schematic [17]

Aside from the high prices of the printing forms, rotogravure printing is also known for evaporation ink finishing. Most printing that utilizes this technique involves inks based on organic solvents. The vapors from organic solvents are harmful to human health and highly flammable. For these reasons, the plants and facilities where rotogravure printing machines are used require special construction and safety measures [14]. Companies operating within the EU are subject to stringent legislation and must be equipped with special types of air purification and solvent recovery devices.

The Aluflexpack Novi Print Shop in Umag printed design samples on the Schiavi Pulsar Printing Machine, 10 group, $1.240 \mathrm{~mm}$ wide with a maximum speed of $350 \mathrm{~m} / \mathrm{min}$, utilizing a rotogravure printing technique on transparent, 12 $\mu$ thick polyester (PET). Aluflexpack Novi utilizes a cutting edge solvent recovery plant and has been awarded the BRC (the British Retail Consortium) and ISO (the International Organisation for Standardisation) production certification.

Siegwerk printing inks (thermal-resistant ink), specifically intended for printing packaging that can later be processed by various methods applied to finished products, were used. Resistances of this ink series are archived by using completely resistant pigments according to ISO 2836 . The printed samples were measured for the values of Vegeta Blue and were compared with the set standard values and predefined color formula. After the printing phase was completed, the laminating process was performed on the Rotomec Rotoconvert Machine with three unwinders (a triplex in a single pass) $1.230 \mathrm{~mm}$ wide, with a maximum speed of $300 \mathrm{~m} / \mathrm{min}$. A Henkel agent and a catalyst were used for lamination. A flexible retort stand-up pouch consists of four different materials: PET, Al, OPA and PP. After lamination, each material has to pass though the cross-linking of materials and solvent evaporation phase which aim to eliminate the problem of residual odor within the packaging material and any de-lamination and migration problems. The Totani BH-60DLLS machine was used to form, seal on three sides (laterally and on the bottom) and die-cut the stand-up pouches, operating at a maximum speed of 1.000 pouches/min. 


\subsection{High Pressure Processing (HPP)}

The processes that may cause unnecessary changes in the packaging's properties and appearance do not always end upon the completion of the graphical and technological process. The packaging, as an integral part of the product, is subject to various food processing regimes, the aggressive parameters which can affect the packaging material's properties.

The application of food high pressure processing in the food industry has developed as an alternative to conventional thermal processes, such as pasteurization and sterilization, aiming to achieve a microbiologically safe product that does not undergo any sensory, physical or nutritional value changes.

High Pressure Processing is a cold pasteurization process in which the final packaged product is exposed in a given chamber to high isostatic pressure (300-600 MPa / 43500 87000 psi), which is applied by water (Fig. 3) [18].

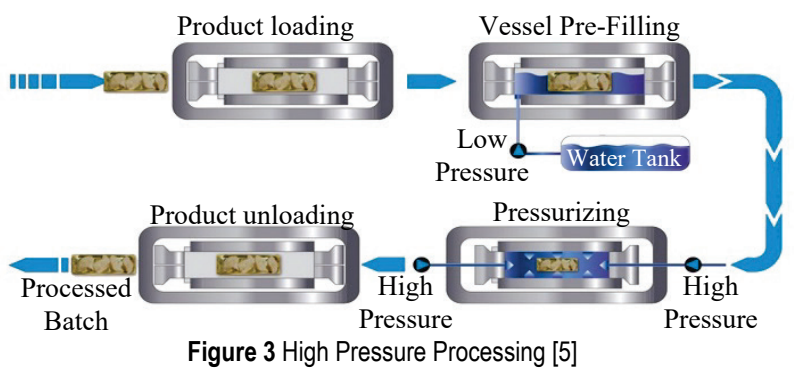

\section{MEASUREMENT RESULTS}

The evaluation of the measured samples within this research was performed on 25 samples for the printing and lamination, and on 24 samples for high pressure processing stages. The total quantity of produced samples was 1000 pieces. High pressure processing was carried out at the University of Zagreb's Faculty of Food Technology and Biotechnology, using a $2 \mathrm{~L}$ volume device manufactured by the Stansted Fluid Power. It applied pressures of 300, 400 and $500 \mathrm{MPa}$ for a defined period of 5 and 10 minutes. The processing temperature remained constant at $22 \pm 1{ }^{\circ} \mathrm{C}$. The pressure rising rate was set at $5 \mathrm{MPa} / \mathrm{s}$ and the release at a maximum of $20 \mathrm{MPa} / \mathrm{s}$. Four samples were processed in each of the pressure and temperature regimes stated above (300, 400 and $500 \mathrm{MPa}$, during 5 and 10 minutes), totaling 24 samples.

Changes in colorimetric values were monitored throughout the printing phase by using a measuring device utilizing the standard formula with the CIE $\mathrm{L}^{*} \mathrm{a}^{*} \mathrm{~b}^{*}$ colorimetric values for the Vegeta Blue spot color. The color was measured with a Hunter Associates Lab. Inc. Device, Type: ColorQuest XE, in Aluflexpack Novi's Print Shop. The device was calibrated to accord with the ISO/IEC 17025:2005 and BS EN ISO 9001:2000 Standards. By measuring the samples after each process stage, starting with printing, the influence of each individual phase on CIE $\mathrm{L}^{*} \mathrm{a}^{*} \mathrm{~b}^{*}$ components in the color space was determined. It was defined at what stage in the process and under which processing regimes, the greatest colorimetric difference occurred and what the most significant differences within the CIE $L^{*} a^{*} b^{*}$ color space were. The average colorimetric difference for each phase was defined in the statistical analysis of the measured values and it was expressed by applying the method of the median mean. Parallel curves were also shown after each measurement stage demonstrating the colorimetric difference values compared to the set color (Figs. 4 and 5).

The measurement was performed on three standard light sources: D65. $/ 10^{\circ}$, A... $/ 10^{\circ}$ and F11./10 . Aluflexpack Novi's Print Shop had previously recorded the CIE L*a*b* Vegeta Blue spot color values that are the subject of the research and the defined formula. For the purposes of this research, the color formula was to a lesser extent modified in its composition and it did not use the original values.

The following standard measuring values were set for Vegeta Blue under three different light sources:

Table 1 Standard Colorimetric values for the Vegeta Blue color

\begin{tabular}{|c|c|c|c|}
\hline Light source & $\mathrm{L}^{*}$ & $\mathrm{a}^{*}$ & $\mathrm{~b}^{*}$ \\
\hline D65./10 & 52.44 & -25.05 & -33.41 \\
\hline A.../10 & 46.06 & -31.96 & -45.96 \\
\hline F11./10 & 46.62 & -16.28 & -41.82 \\
\hline
\end{tabular}

Following the measurement and evaluation of all samples, comparisons of deviations for each process phase were made. The largest colorimetric difference of the Vegeta Blue spot color appeared after the lamination phase. Measurement results were subjected to a statistical analysis and expressed as a median mean which represented the center of mass for the set of 25 pouch samples for printing and lamination and 24 for the high pressure processing stage.

The measured values were obtained by using the following formula:

$\Delta E_{C M C}=\sqrt{\left(\frac{\Delta L}{l S_{L}}\right)^{2}+\left(\frac{\Delta C}{c S_{C}}\right)^{2}+\left(\frac{\Delta H}{S_{H}}\right)^{2}}$

No color tolerance system is perfect, but CMC and CIE94 equations best represent the color differences in the way our eyes see them (Tab. 2) [20].

Table 2 Colorimetric Difference Evaluation Criteria for the Measured Colors

\begin{tabular}{|c|c|}
\hline Tolerance Method & Matching with Visual Perception (\%) \\
\hline CIELAB & $75 \%$ \\
\hline CIELCH & $85 \%$ \\
\hline CIECMC & $95 \%$ \\
\hline
\end{tabular}

Table 3 Average Colorimetric Difference Values for the Vegeta Blue spot color

\begin{tabular}{|c|c|c|}
\hline Stage of the process & Source of light & $\begin{array}{c}\text { Colorimetric } \\
\text { difference CMC2:1 }\end{array}$ \\
\hline \multirow{3}{*}{ Printing } & $\mathrm{D} 65 . / 10^{\circ}$ & 0.23 \\
\cline { 2 - 3 } & $\mathrm{A} . . / 10^{\circ}$ & 0.23 \\
\cline { 2 - 3 } & $\mathrm{F} 11 . / 10^{\circ}$ & 0.30 \\
\hline \multirow{3}{*}{ Lamination } & $\mathrm{D} 65 . / 10^{\circ}$ & 1.56 \\
\cline { 2 - 3 } & $\mathrm{A} . . . / 10^{\circ}$ & 1.71 \\
\cline { 2 - 3 } & $\mathrm{F} 11 . / 10^{\circ}$ & 1.43 \\
\hline \multirow{3}{*}{$\mathrm{HPP}$} & $\mathrm{D} 65 . / 10^{\circ}$ & 1.94 \\
\cline { 2 - 3 } & $\mathrm{A} . . / 10^{\circ}$ & 2.28 \\
\cline { 2 - 3 } & $\mathrm{F} 11 . / 10^{\circ}$ & 2.10 \\
\hline
\end{tabular}


The presented Figs. 4 and 5 show the spectral curves of the measured Vegeta Blue spot color regarding the performed stage of the process. The right part of the picture shows the $\mathrm{L}$ diagram with two wavelengths of color in two phases and the ab diagram shows the color difference between the two phases. The colorimetric difference after printing is within the tolerance limits and amounts to D65. $/ 10^{\circ}$ light source $\mathrm{CMC} 2: 1=0.23$. After lamination, a greater colorimetric difference occurred, the color surpassed the determined tolerance range and the colorimetric difference under the same conditions equaled to $\mathrm{D} 65 . / 10^{\circ} \mathrm{CMC} 2: 1=1.56$ (Fig. 4). After high pressure processing, an even higher colorimetric difference of Vegeta Blue occurred and the average value on the measured samples equaled to D65./10 CMC2:1=1.94. With lamination, Vegeta Blue became darker and crossed into the area of yellow-red. This clearly shows that HPP also influences the Vegeta Blue spot color deviations.

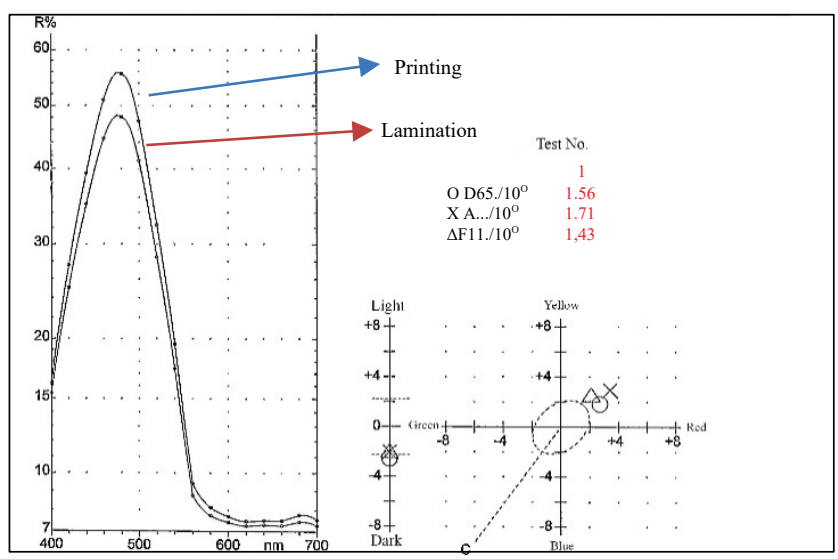

Figure 4 Printing vs Lamination

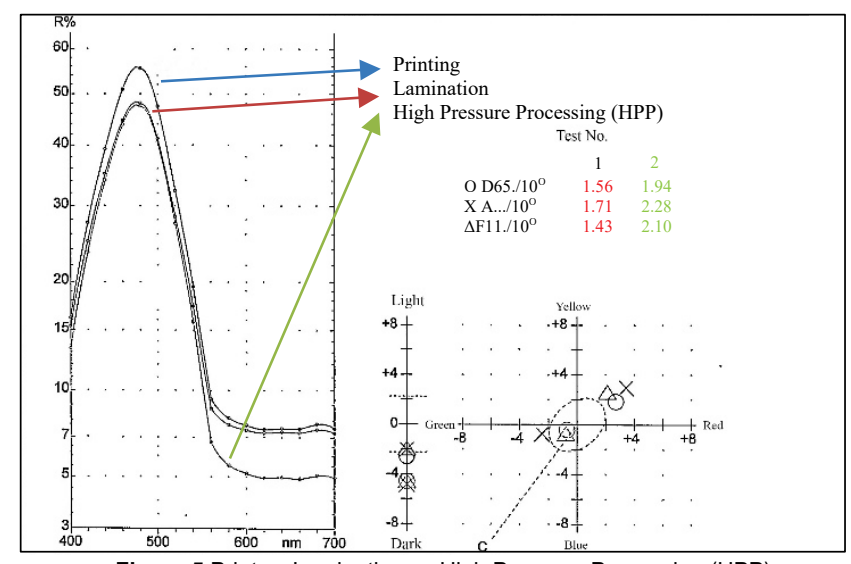

Figure 5 Print vs Lamination vs High Pressure Processing (HPP)

The unacceptable colorimetric difference occurs after the lamination process. By laminating the transparent polyester layer (PET) onto the aluminum surface, a change occurs in all parts of the CIE L*a*b* color system. The problem that arises when the transparent polyester is laminated onto the aluminum surface is inconsistent graphic reproduction, which could be prevented by adjustments to the color recipe. Food packaging is made of different packaging materials and with different printing techniques. Together with different packaging manufacturers and their specific features (printing inks, machine type, substrate, lamination agents, varnishing etc.), the challenge of maintaining color uniformity within the CIE $L^{*} a^{*} b^{*}$ space is sometimes insurmountable. The colorimetric values on a multi-layer flexible packaging containing aluminum and on the packaging containing only transparent polymer materials are not identical. To achieve the identical print, which would mean that the spot color is within the tolerance area, it is necessary to redefine the spot color input formula for every substrate. This, of course, makes the process more complicated and more expensive for print shops, but for the manufacturers of brands that are recognizable by their specific, protected color, the goals is to maintain identical colorimetric values. Specific features of individual packaging materials require that the maximum allowed tolerance area and the standard colorimetric values for the spot color be defined. During the measuring and evaluation of samples, it was noticed that a rather small deviation of the Vegeta Blue spot color, which occurred after lamination $(\Delta E=1.56)$, was more visible than greater deviations of some other colors. After high pressure processing, according to the measured values, Vegeta Blue was darker (Fig. 5).

\section{CONCLUSION}

In order to achieve the desired final effect on the graphical and technological process used for the manufacturing of packaging and marketing of an on-shelf product that attracts customers, every company is faced with a long, complex and well-managed process. It is necessary to define the packaging material's type and composition for every product, which depends on the product's properties, desired shelf life, production lines used for packaging, handling and method of use in addition to a whole range of other factors. Once the material type has been defined, it is also necessary, based on other parameters, to define the printing technique which will be used in the printing of packaging. The choice of printing techniques is largely dependent on the price, volume of the packaging ordered, target quality, further processing of the completed product, etc. Once the printing technique, the packaging material and the print shop that will produce the packaging have been defined, all input parameters have to be agreed upon: the color, separation and allowed colorimetric difference tolerance. If more parameters are defined at the very beginning of the graphical and technological process, the chance of an error and undesired results is reduced to a minimum. For printing, it is recommended to select a packaging manufacturer who applies a standardized and controlled process, which largely facilitates monitoring of packaging through each of the stages and results in a colorimetric difference not exceeding the tolerance area agreed between the ordering party and the packaging manufacturer. Standardization and monitoring of all stages of such a process is the only way packaging can be produced within the defined area of a tolerated colorimetric difference, and meet the goal of the acceptable difference generally invisible to consumers' eyes. 
Increasingly aware and informed consumers now have numerous requirements which they expect from packaging, and these requirements have to be met. Packaging no longer has only a protective or storage function. It is a 'silent seller' on the shelf, contributing to distinction, increasing recognition and is interactive, easy to handle and provides a range of additional benefits such as laser perforation, resealable options, microwave heating or direct consumption. It must comply with the guidelines on sustainable development, environmental protection, etc. At first sight, what the consumer ranks the highest is the color perception and an emotional link with the brand. In order to achieve attractiveness in a shop and draw the initial attention of the consumer, which only lasts a few seconds, a multidisciplinary approach and a highly complex implementation process are necessary.

The goal of the research presented in this paper was to determine the value of the Vegeta Blue spot colorimetric difference that appears on packaging during printing, processing and high pressure processing of the completed product. The Vegeta Blue spot color was measured after these stages and compared with the set standard in order to achieve better qualitative properties for the final product and improve its attractiveness on the shelf. Based on the measurement results, the process stages that provide the highest impact on color deviation were determined. The formula for the Vegeta Blue spot color with its allowed tolerance area $(\Delta E \leq 1)$ was defined as the measurement starting point.

The results were the measured values for the Vegeta Blue spot color. High pressure processing (HPP) causes deviations in the CIE $\mathrm{L}^{*} \mathrm{a}^{*} \mathrm{~b}^{*}$ values of spot color and it increases deviation that is a result of the lamination process. The measurement has shown that the spot colorimetric difference that occurs during the processing phase is lower than the difference that occurs during the lamination stage. During high pressure processing, a change in process colors was also identified (cyan, magenta, yellow and black), in the colors of the dish presented as a part of the design. The changes to process colors were not the subject of the research presented in this paper, but the Company Anilox measured these values against the atlas of the colors applied, specifically to enable further research. It is exactly the process colors for which deviations resulting from sterilization and high pressure processing can be prevented during the graphic preparation and print form design stages.

This Paper has defined the Vegeta Blue spot color value of the colorimetric difference in the CIE L ${ }^{*} a^{*} b^{*}$ color space for printing, lamination and HPP stages. This paper also proposes guidelines to achieve colorimetric difference within the previously defined tolerance ranges for individual colors, and determines those parts of the technological process that have the greatest effect on color deviations.

Every project relating to the inception and creation of packaging is unique and the same rules do not apply to all packaging materials. Complexity and a multi-disciplinary approach add creativity and challenges to each new project. All stages require excellent correlation and communication among the designer, the ordering party and the packaging manufacturer. Within the commissioning company itself, the involvement of several different teams and experts is also necessary in order to prevent any problems on production lines or later during the handling and processing of a product. The fact that industrial production is not the same as the small manufacturing plants of family proprietorships should not be forgotten. Industry seeks to eliminate manual work, machines have high capacities and under ideal conditions, the output control of the packaging manufacturer becomes the input control of the ordering party, but all this presumes error-free packaging items. The shelves in shops today are overcrowded, full of special offer packaging and novelties. It is impossible to determine which of the packaging properties is the most important for the consumer, whether the consumer makes his/her decision consciously or based on emotions linked to a familiar brand. The task for every manufacturer of recognized trademarked products is to achieve uniformity of spot color on different packaging materials, with different printing techniques and with different suppliers. The parameters which influence changes in spot colors are the subject of this paper and they are really numerous in products marketed in several different types of packaging material. There is a difference between printing on a mono material with a white background and a multi-layer flexible material composed with aluminum or metallized foil. For the Vegeta Blue spot color, just like for all other world famous brands, the intended goal is to reach colorimetric values that will be within the desired tolerance area. There are several software solutions which will facilitate the standardization process, but every ordering party should be aware that it is impossible to achieve laboratory conditions in the production plant. It is easy to manage and control standardization with one supplier, on a defined type of packaging material, with a defined type of printing inks, the lamination agent that is always the same, printing forms made with identical parameters and always by the same manufacturer. All this cannot guarantee a perfect result, but any colorimetric difference in such cases has been reduced to a minimum. The reality of food companies is unfortunately slightly different from the described ideal conditions. All manufacturers, for a variety of reasons, use the services of several packaging manufacturers and in such situations, standardization, and subsequently the control of colorimetric values and other packaging characteristics, become more complex and difficult in practice.

The relating research provides a good basis for further research in the area of process color and other packaging material deviations, within the area of printing techniques and processing procedures and other processing methods applied to a finished food product.

\section{REFERENCES}

[1] Kotler, P. \& Armstrong, G. (2012). Principles of Marketing. $14^{\text {th }}$ Ed. Upper Saddle River, New Jersey: Pearson Prentice Hall.

[2] Govers, P. C. M. \& Schoormans, J. P. L. (2005). Product personality and its influence on consumer preference. Journal of Consumer Marketing, 22(4), 189-197. https://doi.org/10.1108/07363760510605308 
[3] Young, T. K., Byungjin, M., \& Kyung, W. K. (2014) General Characteristics of Packaging Materials for Food System. In Jung, H.H. (Eds.) Innovations in Food Packaging, 13-20. Elsevier Ltd. https://doi.org/10.1016/B978-0-12-394601-0.00002-3

[4] Welti-Chanes, J., López-Malo, A., Palou, E., et al. (2005). Fundamentals and Applications of High Pressure Processing of Foods. Novel Food Processing Technologies. New York: CRC Press.

[5] HPP Technology: What is High Pressure? (5 $5^{\text {th }}$ February 2018). Retrived from https://www.hiperbaric.com/en/ highpressure

[6] Galić, K., Ciković, N., \& Berković, K. (2000). Analiza ambalažnog materijala. Zagreb, Hrvatska: Hinus d.o.o.

[7] Značenje pojmova iz Pravilnika o ambalaži, Savjetodavna služba HOK-a, (5 $5^{\text {th }}$ May 2018). Retrived from http://infos.hok.hr/faq/f_tehnicka_pitanja/f9_zastita_okoline/z nacenje_pojmova_iz_pravilnika_o_ambalazi

[8] The Future of Packaging: Long Term Strategic Forecasts to 2028, Smithers Pira. (2018, October $\left.5^{\text {th }}\right)$. Retrived from https://www.smitherspira.com/industry-market-reports/ packaging/packaging-long-term-strategic-forecasts-to-2028

[9] Vujković, I. A. (1997). Polimerna i kombinovana ambalaža. Novi Sad, Srbija: Poli.

[10] Briston, J. H. (1990). Plastics Film. $3^{\text {rd }}$ Ed. Essex, United Kingdom: Longman Scientific \& Technical.

[11] Proposal for a Directive of the European Parliament and of the Council, (28 $8^{\text {th }}$ May 2018). Retrived from http://ec.europa.eu/environment/circular-economy/pdf/singleuse_plastics_proposal.pdf

[12] Plastics - the Facts 2016. (18 ${ }^{\text {th }}$ Dec. 2017). Retrived from https://www.plasticseurope.org/en/resources/publications/3plastics-facts-2016

[13] Bassin, S. B. (1988). Value-Added Packaging Cuts through Store Clutter, Marketing News, September $26^{\text {th }}$, pp. 21.

[14] Bolanča, S. (2013). Tisak ambalaže. Zagreb, Hrvatska: Sveučilišna naklada.

[15] Valdec, D., Miljković, P., \& Auguštin, B. (2017). The influence of printing substrate properties on color characterization in flexography according to the ISO specifications, Tehnički glasnik, 11(3), 73-77.

[16] Anyadike, N. (2003). Introduction to Flexible Packaging. Surrey, UK: Pira International Ltd.

[17] Oldenzijl, R., Gaitens, G. and Dixon, D. (2010). Conduct Radio Frequencies with Inks, Radio Frequency Identification Fundamentals and Applications Design Methods and Solutions, Cristina Turcu (Ed.), ISBN: 978-953-7619-72-5, InTech, Retrived from: http://www.intechopen.com/books/ radio-frequencyidentification-fundamentals-and-applicationsdesign-methods-and-solutions/conduct-radio-frequencieswithinks. https://doi.org/10.5772/7982

[18] Food Safety, High Pressure Processing of Foods, Authority of Ireland, (September 2015). Retrived from https://www.fsai.ie/ publications_high_pressure_processing/

[19] Kuehni, R. G. (2003). Color space and its divisions: color order from antiquity to the present. New Jersey: John Wiley \& Sons. https://doi.org/10.1002/0471432261

[20] A Guide to Understanding Color, x-Rite Pantone. (2016). Retrived from https://www.xrite.com/-/media/xrite/files/ whitepaper_pdfs/110-001_a_guide_to_understanding_color_ communication/110-001_understand_color_en.pdf
Authors' contacts:

Renata TOMERLIN, MSc

Podravka d.d. (plc),

Ante Starčevića 32,

48000 Koprivnica, Croatia

E-mail: renata.tomerlin@podravka.hr

Mario TOMIŠA, PhD, Assoc. Prof.

University North,

Trg dr. Žarka Dolinara 1,

48000 Koprivnica, Croatia

E-mail: mario.tomisa@unin.hr

Damir VUSIĆ, PhD, Assoc. Prof.

University North,

Jurja Križanića 31b,

42000 Varaždin, Croatia

E-mail: damir.vusic@unin.hr 